\title{
Reúso de efluentes sanitários e suas implicações nos atributos químicos do solo
}

\section{Rafael Carvalho de Souza*, André Victor Silveira, Luana Mattos de Oliveira Cruz, Jerusa Schneider}

\section{Resumo}

O presente projeto tem como objetivo avaliar as alterações químicas no solo após aplicação de efluente sanitário, verificando a potencialidade de reúso, considerando o grau de restrição de uso em termos de salinidade, sodicidade e toxicidade de elementos químicos específicos. Para isso, foi conduzido um experimento em escala de bancada e realizadas aplicações de diferentes porcentagens dos efluentes, sendo um ensaio controle (não recebeu efluente), e outros com aplicação de 25,75 e $100 \%$ do efluente. Constatou-se que, mesmo com aplicação de $100 \%$ do efluente, não promoveu condições salinas e sódicas nas amostras de solo, bem como, não apresentou elementos tóxicos que impossibilite o reuso.

\section{Palavras-chave: \\ Esgoto tratado, Reúso de água, Salinização}

\section{Introdução}

O reúso da água é hoje um fator importante para a gestão dos recursos hídricos, com objetivo de suprir os gargalos que ainda existem na gestão da água. Atualmente, a maioria dos estudos sobre avaliação dos serviços ecossistêmicos não considera o componente "solo" ou, quando considera, o faz de maneira pouco clara ou muito generalizada. Portanto, uma questão importante que está sendo discutida atualmente é a avaliação da qualidade do solo. Sendo assim, o presente trabalho teve como objetivo avaliar as alterações químicas no solo após aplicação de efluente sanitário proveniente da Estação de Tratamento de Esgoto de Barão Geraldo e uma amostra de lençol freático próxima ao Rio Araguaia, localizado no estado de Goiás.

\section{Resultados e Discussão}

Amostras de solo da região do projeto de irrigação Luiz Alves do Araguaia foram inicialmente caracterizadas química e fisicamente em laboratório. Além disso, amostras dos efluentes foram avaliados verificando a potencialidade de reuso, considerando o grau de restrição de uso em termos de salinidade, sodicidade e toxicidade de elementos químicos específicos (Tabela 1).

Tabela 1. Atributos químicos do lençol freático e do efluente tratado.

\begin{tabular}{|c|c|c|c|c|}
\hline \multirow{2}{*}{ Atributos químicos } & \multicolumn{2}{|c|}{ Lençol Freático } & \multicolumn{2}{c|}{ Efluente Tratado } \\
\cline { 2 - 5 } & Média & $\begin{array}{c}\text { Desvio } \\
\text { Padrão }\end{array}$ & Média & $\begin{array}{c}\text { Desvio } \\
\text { Padrão }\end{array}$ \\
\hline $\mathrm{pH}$ & 6,99 & 0,09 & 6,73 & 0,03 \\
\hline $\mathrm{CE} / \mathrm{c} / \mathrm{cm}$ & 40 & 5 & 53,33 & 2,887 \\
\hline Alcalinidade Total & 53,33 & 2,887 & 68,33 & 2,887 \\
\hline Turbidez Parcial & 619,33 & 20,502 & 772,67 & 17,243 \\
\hline Cor Aparente Unid. Cor & 5,8 & 0,062 & 34,84 & 5,778 \\
\hline $\mathrm{DQO} \mathrm{mg} O_{2} / L$ & 10 & 9,165 & 68 & 12,124 \\
\hline
\end{tabular}

Por fim, foi conduzido um experimento em escala de bancada e realizadas aplicações de diferentes porcentagens dos efluentes, sendo: T0 - tratamento testemunha, para efeito comparativo (100\% água da rede de abastecimento); T1 - (75\% água da rede de abastecimento $+25 \%$ efluente); T2 - (25\% água da rede de abastecimento $+75 \%$ efluente) e T3 - (100\% efluente). As aplicações de diferentes porcentagens dos efluentes foram conduzidos em escala de bancada, em vasos de aproximadamente $0,500 \mathrm{~L}$ e em triplicata. Os parâmetros analisados foram a condutividade elétrica e os índices de RAS e PST, seguindo critérios de Richards (1964) e Pizarro (1978) (Tabela 2).

Tabela 2. Atributo químicos do solo após aplicação do efluente sanitário.

\begin{tabular}{|c|c|c|c|c|c|c|c|c|c|c|c|c|}
\hline \multirow{2}{*}{ Atributos químicos } & \multicolumn{4}{|c|}{ Após 15 dias } & \multicolumn{4}{|c|}{ Após 30 dias } & \multicolumn{4}{|c|}{ Após 60 dias } \\
\hline & To & T1 & $\mathrm{T} 2$ & T3 & TO & T1 & $\mathrm{T} 2$ & $\mathrm{~T} 3$ & TO & T1 & T2 & T3 \\
\hline $\mathrm{pH}$ & 4,9 & 5,5 & 5,7 & 6 & 4,9 & 6,7 & 5,3 & 5,7 & 4,9 & 5,7 & 5,5 & 5,8 \\
\hline $\mathrm{dS} / \mathrm{m}$ & 0,13 & 0,20 & 1,60 & 0,40 & 0,13 & 0,40 & 0,50 & 1,50 & 0,13 & 0,80 & 0,50 & 1,70 \\
\hline $\mathrm{Ca} \quad \mathrm{mmold} / \mathrm{dm} B$ & 5 & 69 & 164 & 59 & 5 & 99 & 59 & 99 & 5 & 264 & 59 & 90 \\
\hline Mg $\quad$ mmoldddm3 & 1 & 20 & 14 & 8 & 1 & 16 & 16 & 13 & 1 & 20 & 8 & 11 \\
\hline Na $\quad m$ mold d dm3 & 0,5 & 1 & 4 & 4,8 & 0,5 & 1 & 3 & 9 & 0,5 & 0,4 & 4 & 16 \\
\hline$H+A l$ mmold dmB & 54 & 25 & 25 & 25 & 54 & 9 & 22 & 21 & 54 & 23 & 29 & 17 \\
\hline$g / \mathrm{dm} B$ & 45 & 42 & 86 & 22 & 45 & 29 & 10 & 53 & 45 & 115 & 27 & 41 \\
\hline C.T.C mmolddmB & 61 & 119 & 212 & 99,5 & 61 & 135 & 103 & 146 & 61 & 313 & 104 & 136 \\
\hline$\%$ & 12 & 79 & 88 & 75 & 12 & 93 & 79 & 86 & 12 & 93 & 72 & 88 \\
\hline Relaçöes calculadas & To & $\mathrm{T} 1$ & $\mathrm{~T} 2$ & $\mathrm{~T}_{3}$ & To & $\mathrm{T} 1$ & $\mathrm{~T} 2$ & $\mathrm{~T} 3$ & T0 & $\mathrm{T} 1$ & $\mathrm{~T} 2$ & $\mathrm{~T} 3$ \\
\hline RAS & 0,83 & 0,15 & 0,42 & 0,83 & 0,83 & 0,13 & 0,49 & 1,20 & \begin{tabular}{|l|l|}
0,83 \\
\end{tabular} & 0,33 & 0,69 & 2,25 \\
\hline PST & 0,29 & 0,84 & 1,89 & 4,82 & 0,29 & $|0,74|$ & 2,91 & 6,15 & $|0,29|$ & 0,13 & \begin{tabular}{|l|l|} 
& \\
\end{tabular} & 11,70 \\
\hline
\end{tabular}

\section{Conclusão}

A aplicação do efluente no solo incrementou os atributos já existentes do mesmo, como a concentração de cátions, condutividade elétrica, quantidade de matéria orgânica entre outros. Entretanto, com base nas relações estudadas pelos autores supracitados, constata-se que o solo não se tornou um solo salino e/ou sódico. De tal forma, a utilização do efluente da ETE Barão Geraldo como água de reúso se mostra uma alternativa válida, pois poupa recursos ambientais e não acarreta grandes danos ao solo.

PIZARRO, F. Drenage agrícola y recuperacion de suelos salinos. Madrid: Editorial Agrícola Española, 1978. 525 p.

RICHARDS, L.A. Diagnosis and improvement of saline and alkali soils. Washington: U.S. Salinity Laboratory Staff, USDA 1954. 160p. (Agriculture Handbook, 60). 